\title{
Iatrogenic arteriovenous fistula of the breast as a complication of core needle biopsy
}

\author{
MHR Haider, A Satpathy, W Abou-Samra
}

Betsi Cadwaladr University Health Board, UK

ABSTRACT

Ultrasonography guided core biopsy has become the standard of care in the assessment of breast cancer. Although the procedure is associated with low rates of complications, we present a case report of a rare complication of the procedure that has been reported only once previously in the medical literature.

\section{KEYWORDS}

Iatrogenic - Arteriovenous fistula - Breast

Accepted 29 April 2014; published online XXX

CORRESPONDENCE TO

Muhammad Haider, E: drhasnainraza@hotmail.com

\section{Case History}

A 37-year-old woman (a nurse by profession) presented to the rapid access breast clinic with a lump in the right breast that had been palpable for two weeks. Her past medical history was notable for excision of fibroadenomas from both the breasts 18 years earlier. Examination was suggestive of a firm lump in the upper inner quadrant of the right breast. She underwent bilateral mammography (Fig 1) followed by ultrasonography of the breast (Fig 2). The ultrasonography was suggestive of a $10 \mathrm{~mm}$ well defined hypoechoic area typical of a fibroadenoma. As she was quite anxious about the nature of this swelling, ultrasonography guided core biopsy of the lesion was performed. The procedure was tolerated well without any reported complications. Histopathology result of the lesion was suggestive of a pericanalicular fibroadenoma. She was discharged after discussion in the multidisciplinary breast meeting.

Two weeks after the biopsy, the patient presented to the breast clinic again with a strange buzzing sensation in the right breast. Clinical examination revealed symmetrical breasts without any visible distortion or lumps. There was no breast or arm swelling on the ipsilateral side. There was no visible bruising or signs of inflammation although on palpation, a pulsatile swelling in the area of biopsy was noted. Auscultation revealed continuous machinery murmur over the upper inner quadrant (ie the area of the previous biopsy). A provisional diagnosis of an iatrogenic arteriovenous (AV) fistula was made, which was later confirmed on Doppler imaging of the breast (Fig 3) to be an area of high velocity flow with prominent vessels.

After discussion with the patient, a plan was made to follow her up clinically without any surgical intervention. In the case of deterioration, she was to be referred for vascular intervention for clipping of the fistula.

The patient was followed up in the breast clinic with progressive disappearance of symptoms and at the last follow-up visit, no pulsatile mass was palpable. She was eventually discharged.

\section{Discussion}

Ultrasonography guided core biopsy is a procedure with high sensitivity for evaluation of breast lumps ${ }^{1}$ and it has become the standard of care in the assessment of breast cancer. ${ }^{2}$ It is associated with low rates of complications. ${ }^{3}$

Acquired AV fistulas of the breast are quite rare. A PubMed search of the literature with search terms of 'acquired, arteriovenous fistula, breast' showed only one case report, by Joseph et al, that was representative of a true iatrogenic AV fistula of the breast. ${ }^{4}$ The search was repeated after replacing 'acquired' with 'iatrogenic' but the same results were obtained. Our case showed a few similarities with Joseph et al's patient.

It was interesting to note that both the patients were nurses in their 30s (34 and 37 years). Both had previous history of excisional biopsies for benign breast disease in the same quadrant (upper inner quadrant of the breast). These similarities signify a higher level of vigilance, an expectation for tissue diagnosis and anxiety on part of the medical team as well. The similarity of the upper inner quadrant of the breast signifies the position of medial perforator vessels and possible injury to the vessels at the time of needle biopsy.

The differences in the two cases were that our case presented early compared with the already published case. 

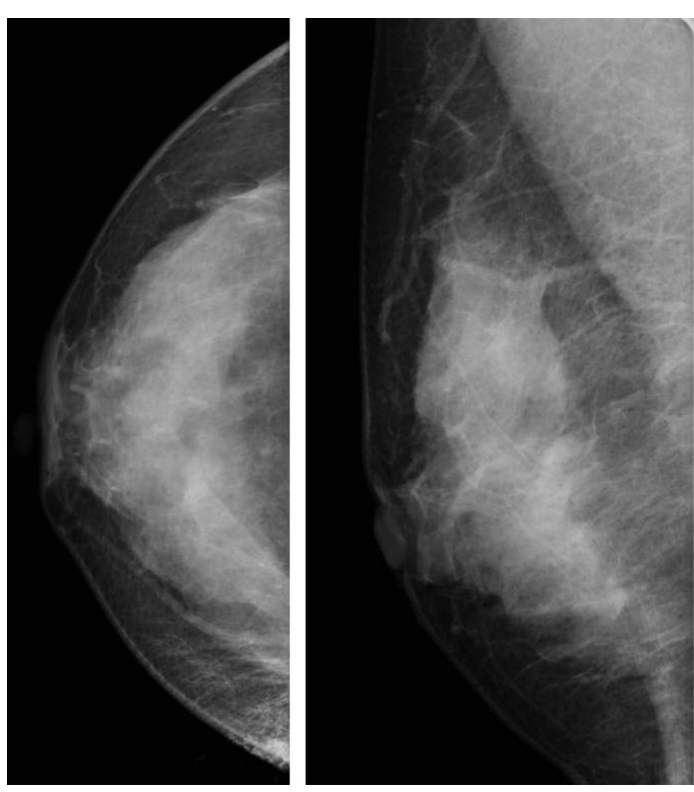

Figure 1 Craniocaudal and mediolateral mammography of the right breast

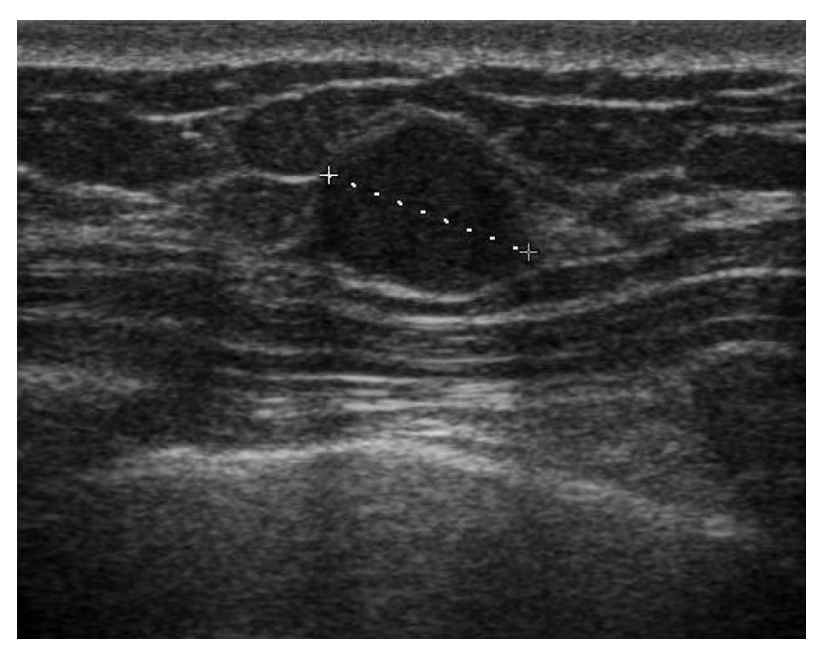

Figure 2 Ultrasonography of the right breast

Furthermore, in our case, the patient recovered without any surgical intervention.

Other reported cases included that of a congenital AV fistula and true aneurysm of the internal thoracic artery in a 56-year-old woman. ${ }^{5}$ There were also a number of case reports with acquired AV fistulas resulting in unilateral or bilateral breast enlargement. ${ }^{6-8}$ Most of these were cases of renal failure requiring $\mathrm{AV}$ fistulas for haemodialysis. One such patient developed pleural effusion in addition to arm and breast swelling. ${ }^{9}$

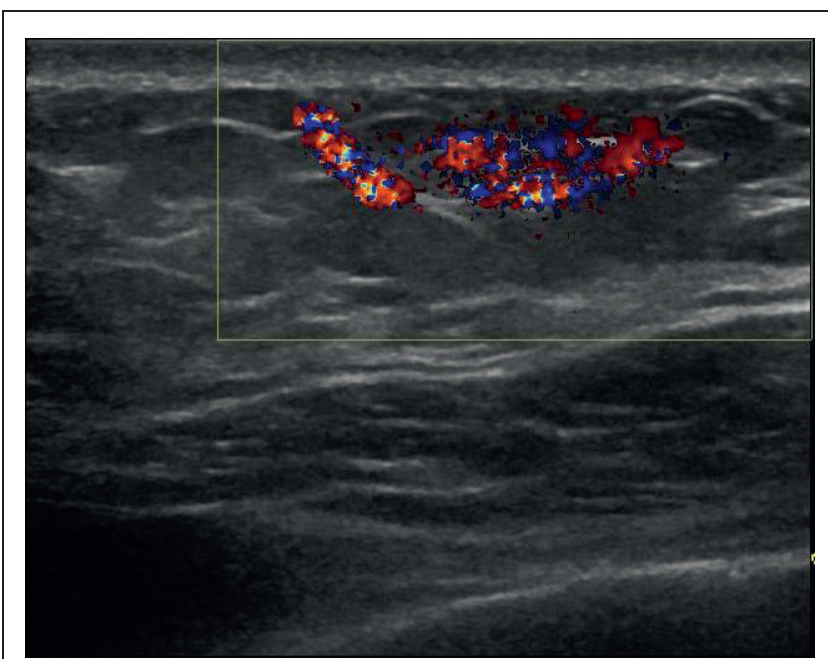

Figure 3 Doppler imaging of the right breast

It was evident from these case reports that placement of permanent $\mathrm{AV}$ access or temporary subclavian dual lumen catheters for haemodialysis can be associated with significant oedema of the arm or breast due to venous occlusion. Breast enlargement associated with haemodialysis AV fistulas, especially in the presence of a history of subclavian vein catheterisation, may be indicative of ipsilateral subclavian vein stenosis/thrombosis.

We also came across a case report of a congenital AV fistula in the breast of a young woman who presented with a murmur, a palpable lump and the presence of varicose-like veins in the breast. ${ }^{10}$ Arteriography revealed an AV fistula in the left breast. The lesion was corrected surgically. One of the cases presented with subcutaneous pseudoaneurysmal development of an internal mammary AV fistula after sternal wire closure. ${ }^{11}$ The lesion underwent progressive thrombosis and was resected. There are also case reports of AV fistulas secondary to thoracic trauma that required surgical intervention. ${ }^{12,13}$

\section{Conclusions}

Acquired AV fistulas of the breast are quite rare. This complication can occur if the area of injury or surgical intervention is in proximity to the vascular bundle. Identification of perforators before attempting core biopsy can avoid injury and development of AV fistulas. We also recommend discussing this complication before the procedure in these areas in the breast.

\section{References}

1. Rouse HC, Ussher S, Kavanagh AM, Cawson JN. Examining the sensitivity of ultrasound-guided large core biopsy for invasive breast carcinoma in a population screening programme. J Med Imaging Radiat Oncol 2013; 57: 435-443.

2. Dillon MF, Hill AD, Quinn CM et al. The accuracy of ultrasound, stereotactic, and clinical core biopsies in the diagnosis of breast cancer, with an analysis of false-negative cases. Ann Surg 2005; 242: 701-707. 
3. Prutki M, Stern-Padovan R, Jakić-Razumović J et al. Ultrasound guided breast biopsy - a retrospective study and literature review. Lijec Vjesn 2012; 134 270-275.

4. Joseph KA, Ditkoff BA, Komenaka I et al. Acquired arteriovenous fistula of the breast. Breast J 2004; 10: 156-158.

5. Cil AS, Bozkurt M, Bozkurt DK, Karabacak A. Coexistence of the congenital arteriovenous fistula of the left breast with a true aneurysm of the right internal mammary artery. Clin Med Res 2013; 11: 237-241.

6. Gadallah MF, el-Shahawy MA, Campese VM. Unilateral breast enlargement secondary to hemodialysis arteriovenous fistula and subclavian vein occlusion. Nephron 1993; 63: 351-353.

7. Lombi F, García A, Young P et al. Unilateral breast enlargement due to a highflux ipsilateral hemodialysis fistula. J Vasc Access 2010; 11: 169-170.

8. Goo DE, Kim YJ, Choi DL et al. Bilateral breast enlargement: an unusual presentation of superior vena cava obstruction in a hemodialysis patient with fibrosing mediastinitis. Cardiovasc Intervent Radiol 2011; 34: S195-S197.
9. Wright RS, Quinones-Baldrich WJ, Anders AJ, Danovitch GM. Pleural effusion associated with ipsilateral breast and arm edema as a complication of subclavian vein catheterization and arteriovenous fistula formation for hemodialysis. Chest 1994; 106: 950-952.

10. Vlahos L, Prunzos P, Kailidou E et al. Congenital A-V fistula of the breast. Radiologe 1991; 31: 250-252.

11. Deuvaert FE, Dumont N, Van Nooten G et al. Poststernotomy arteriovenous fistula of internal mammary origin with pseudoaneurysmal subcutaneous extension. J Cardiovasc Surg 1987; 28: 343-344.

12. Ishikawa T, Brown GR. Traumatic arteriovenous fistula of the internal mammary artery. J Trauma 1977; 17: 978-980.

13. Szymanski TJ, Llera JL. Traumatic thoracic aorta-innominate vein fistula: a case report. Ann Emerg Med 1986; 15: 466-469. 